\title{
BMJ Open Socioeconomic inequalities in the delivery of brief interventions for smoking and excessive drinking: findings from a cross-sectional household survey in England
}

Colin Angus, ${ }^{\oplus 1}$ Jamie Brown, ${ }^{\oplus 2}$ Emma Beard, ${ }^{\circledR 3}$ Duncan Gillespie, ${ }^{\oplus 1}$

Penelope Buykx, ${ }^{\oplus 1}$ Eileen F S Kaner, ${ }^{\bullet 4}$ Susan Michie, ${ }^{\circ 5}$ Petra Meier ${ }^{\oplus 1}$

To cite: Angus C, Brown J, Beard E, et al. Socioeconomic inequalities in the delivery of brief interventions for smoking and excessive drinking: findings from a cross-sectional household survey in England. BMJ Open 2019;9:e023448. doi:10.1136/ bmjopen-2018-023448

- Prepublication history and additional material for this paper are available online. To view these files, please visit the journal online (http://dx.doi org/10.1136/bmjopen-2018023448).

Received 6 April 2018

Revised 24 January 2019 Accepted 18 February 2019

Check for updates

(C) Author(s) (or their employer(s)) 2019. Re-use permitted under CC BY-NC. No commercial re-use. See rights and permissions. Published by BMJ.

For numbered affiliations see end of article.

Correspondence to

Colin Angus;

c.r.angus@sheffield.ac.uk

\section{ABSTRACT}

Objectives Brief interventions (BI) for smoking and risky drinking are effective and cost-effective policy approaches to reducing alcohol harm currently used in primary care in England; however, little is known about their contribution to health inequalities. This paper aims to investigate whether self-reported receipt of $\mathrm{BI}$ is associated with socioeconomic position (SEP) and whether this differs for smoking or alcohol.

Design Population survey of 8978 smokers or risky drinkers in England aged 16+ taking part in the Alcohol and Smoking Toolkit Studies.

Measures Survey participants answered questions regarding whether they had received advice and support to cut down their drinking or smoking from a primary healthcare professional in the past 12 months as well as their SEP, demographic details, whether they smoke and their motivation to cut down their smoking and/or drinking. Respondents also completed the Alcohol Use Disorders Identification Test (AUDIT). Smokers were defined as those reporting any smoking in the past year. Risky drinkers were defined as those scoring eight or more on the AUDIT. Results After adjusting for demographic factors and patterns in smoking and drinking, BI delivery was highest in lower socioeconomic groups. Smokers in the lowest social grade had $30 \%$ (95\% Cl 5\% to 61\%) greater odds of reporting receipt of a $\mathrm{BI}$ than those in the highest grade. The relationship for risky drinking appeared stronger, with those in the lowest social grade having $111 \%$ (95\% Cl $27 \%$ to $252 \%$ ) greater odds of reporting BI receipt than the highest grade. Rates of BI delivery were eight times greater among smokers than risky drinkers $(48.3 \%$ vs $6.1 \%)$.

Conclusions Current delivery of $\mathrm{BI}$ for smoking and drinking in primary care in England may be contributing to a reduction in socioeconomic inequalities in health. This effect could be increased if intervention rates, particularly for drinking, were raised.

\section{INTRODUCTION}

Tobacco smoking and the excessive consumption of alcohol are leading causes
Strengths and limitations of this study

- Used data from a large representative sample of adult smokers and drinkers in England.

- Based on data on intervention receipt reported by patients, rather than practitioners.

- Analysis controls for a broad range of potentially confounding demographic factors.

- Respondents may have underestimated or misreported their drinking or smoking.

- There may be additional socioeconomic gradients in intervention effectiveness, which could moderate the overall impact of brief interventions on health inequalities.

of preventable disease both in the UK and worldwide $^{1}$ and inequalities in both alcohol-related and tobacco-related health harms are a significant contributor to wider inequalities in health. ${ }^{23}$ Underlying these inequalities are conflicting socioeconomic patterns in the behaviours themselves. Smoking prevalence and related harm both increase with deprivation, ${ }^{4}$ while for alcohol consumption the picture is more complex. Those in more deprived groups are more likely to abstain from drinking, and those who drink are more likely to drink within the UK drinking guidelines compared with less deprived groups, ${ }^{5}$ while those in more deprived groups who drink heavily, drink more on average than heavy drinkers in less deprived groups. ${ }^{6}$ This, in part, has meant that numerous studies have found alcohol consumption to be lower in more deprived groups even though they suffer greater levels of alcohol-related harm, ${ }^{278}$ a phenomenon referred to as the 'alcohol harm paradox'. ${ }^{79}$

Screening and brief interventions (BIs), consisting of an initial case finding or 
screening step followed by delivery of feedback and structured advice or behaviour change counselling, delivered in primary care, is an effective and cost-effective measure to increase smoking cessation rates ${ }^{10} 11$ and reduce harmful drinking. ${ }^{12}{ }^{13}$ Current UK clinical guidelines recommend that all patients are assessed for smoking annually, with a BI delivered to all smokers. ${ }^{14}$ Guidance for alcohol encourages the use of opportunistic screening and BI alongside requirements to screen all patients registering with a new primary care provider or attending a health check. ${ }^{1516}$ In spite of this guidance, BI delivery levels remain low in England, ${ }^{17}$ particularly for alcohol, ${ }^{18}$ a finding that has been replicated in many

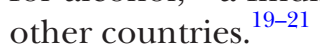

Research across a broad range of interventions and settings has found that public health policies, including screening programmes in primary care, may exacerbate inequalities in health even while improving population health overall. ${ }^{22}{ }^{23}$ In this context, it is striking that very little research to date has considered the potential for BI programmes for tobacco or alcohol to affect inequalities, particularly given the high socioeconomic variation in poor health due to both behaviours. We aimed to address this gap by examining whether there are sociodemographic gradients in BI delivery for smoking and drinking and whether these can be explained by sociodemographic or behavioural characteristics of patients attending primary care in England.

\section{METHODS}

\section{Data sources}

The Alcohol and Smoking Toolkit Studies are large, nationally representative, monthly surveys of adults aged $16+$ in England. ${ }^{24}$ A sample of approximately 1700 respondents each month participate in household computer-assisted interviews. The survey uses a form of random location sampling, representing a hybrid between random probability and simple quota sampling (see published protocols for further details ${ }^{24}$ ). We used data collected between March 2014 and July 2016 $(\mathrm{n}=48808)$ with analysis restricted to respondents who reported visiting the general practitioner (GP) in the past 12 months and were either smokers (those reporting that they had smoked cigarettes or other tobacco products at least occasionally in the past year-see online supplementary file for full details) or risky drinkers (those scoring at least eight on the Alcohol Use Disorders Identification Test [AUDIT] ${ }^{26}$ ). This gave a total sample of 9042 adults of whom 5004 were smokers only, 2528 were risky drinkers only and 1446 were both (data on the smoking status of one risky drinker and the drinking status of 63 smokers were missing).

\section{Measures}

Our primary outcome measure was self-reported receipt of a BI (or more intensive intervention) from a GP or other primary care-based health worker in the past year. Respondents who smoked were asked, 'Has your GP spoken to you about smoking in the past year?' and $\mathrm{BI}$ receipt was categorised as a response of at least 'Yes, he/she advised me to stop but did not offer anything'. Risky drinkers were asked, 'In the last 12 months has a doctor or other health worker within your GP surgery discussed your drinking?', with BI receipt categorised as a response of at least 'Yes, a doctor or other health worker within my GP surgery offered advice about cutting down my drinking'. Note that this definition includes referral to specialist treatment as recommended for those with potential alcohol dependence. See online supplementary file for a full list of response options.

Data were also collected on respondents' age, gender, region of England (categorised as North, Midlands or South), the number of children in the household (categorised as 0 or $1+$ ), self-reported disability status (disability/no disability) and ethnicity (white, mixed/ multiple ethnic group, Asian or British Asian, black and other). Self-reported motivation to reduce smoking and drinking was recorded and grouped into those responding 'I don't want to stop smoking/cut down on drinking', those reporting some degree of motivation to quit/cut down and those who were highly motivated and willing to specify a time frame for cutting down-'I really want to stop smoking and intend to in the next month/3 months'.

As previous studies have identified that different measures of socioeconomic position (SEP) demonstrate different relationships with alcohol consumption, ${ }^{69}$ we examined four alternative measures SEP:

1. Social grade, classified using the British National Readership Survey Social-Grade Classification Tool $^{27}$ : A: higher managerial, administrative or professional; B: intermediate managerial, administrative or professional; C1: supervisory or clerical and junior managerial administrative or professional; C2: skilled manual workers; D: semiskilled and unskilled manual workers and E: causal or lowest grade workers, pensioners and others who depend on the welfare state for their income.

2. Educational level, grouped as: university education, A-level and equivalent, General Certificate of Secondary Education (GCSE)/vocational, other/still studying and none.

3. Working status, categorised as: being in full-time employment or otherwise.

4. Housing tenure, categorised as: owner-occupied (owned outright or being brought with a mortgage) or otherwise.

Finally, in order to test whether higher levels of alcohol consumption increase the likelihood of receiving a $\mathrm{BI}$, the risky drinker group were further subdivided according to their AUDIT score, in line with WHO guidelines ${ }^{26}$ :

- 8-15-Risky drinker.

- 16-19-High-risk drinkers.

- 20+-Possible alcohol dependence. 


\section{Analysis}

Data were weighted using an iterative 'rim weighting' technique as used in previous analyses of Smoking and Alcohol Toolkit data (eg, ref 18). Parallel analysis using unweighted data is reported in the online supplementary material (online supplementary table S1-7 and figure S1). Missing data were imputed using multiple imputation with 20 data sets ${ }^{28}$ and analytical results combined using Rubin's rules. ${ }^{29}$ Complete case only analyses are reported in the online supplementary material (online supplementary table S8-13 and figure S2). All imputation and analyses were undertaken using Stata V.12 ${ }^{30}$ following a plan preregistered with the Open Science Framework prior to any data analysis (https://osf.io/5eq4h/). As the only continuous variable in the analysis, age was standardised and tested for non-linearity using the Box-Tidwell approach. $^{31}$ This suggested significant non-linearity and age was, therefore, categorised into six groups (18-24, 25-34, 35-44, 45-54, 55-64 and 65+).

The analysis consisted of four steps:

1. We produced descriptive tables, the full data set showing rates of smoking and risky drinking (all respondents scoring AUDIT 8+) in the population and rates of GP attendance and $\mathrm{BI}$ receipt for those who visited their GP for both smokers and risky drinkers, stratified by the four socioeconomic measures to show the extent to which socioeconomic inequalities exist before adjusting for demographic and other factors.

2. To examine the extent to which variation in BI delivery among those at risk and attending primary care in the past year can be explained by demographic characteristics alone, we fitted two multivariable logistic regression models in which receipt of a smoking or alcohol intervention was regressed on age, gender, region, number of children in the household, disability status and ethnicity. These models also include a linear (monthly) temporal trend to assess whether BI rates have increased or decreased over the data collection period.

3. To examine the extent to which drinking and smoking behaviour, and motivations to cut down can explain additional variation in BI delivery, we fitted two further multivariable models, which additionally adjust for drinking status (risky vs non-risky) and motivation to stop smoking (in the smoking model) or smoking status (smoker vs non-smoker), AUDIT group and motivation to cut down drinking (in the drinking model).

4. To examine whether SEP can explain any remaining variation in BI delivery, we fitted fully adjusted models in which each of the four measures of SEP was added separately.

\section{Patient and public involvement}

Neither patients nor the public was involved in the design of this study. Strengthening the Reporting of Observational Studies in Epidemiology guidelines were followed throughout. $^{32}$
RESULTS

\section{Descriptive statistics}

Demographic characteristics for the 9042 smokers and risky drinkers included in the analytic sample are presented in table 1 . This shows a relatively even spread of both smokers and risky drinkers across the life course, except for the youngest age group (18-24years old), which has a greater concentration of risky drinkers. Smokers are more likely to be female and more likely to live with children or have a disability than risky drinkers. The other key distinction comes in terms of motivation to cut down or quit, with $67.4 \%$ of smokers reporting some motivation to reduce their smoking compared with only $39.4 \%$ of risky drinkers.

Descriptive analyses (table 2) show that overall smoking was more prevalent than risky drinking (20.5\% vs $13.1 \%$ of the adult population). There were also marked socioeconomic gradients in prevalence, with smoking increasingly common in lower socioeconomic groups (eg, 35.7\% of social grade $\mathrm{E}$ respondents compared with $11.5 \%$ in grade $A B$ ), while the gradient in risky drinking was less stark and in the opposite direction $(11.3 \%$ in grade $\mathrm{E}$ compared with $14.3 \%$ in grade $\mathrm{AB}$ ). These gradients were seen most clearly for social grade, although similar patterns existed for education, but were not evident when using employment for smokers and housing tenure for drinkers. There were no clear gradients for GP attendance, although risky drinkers were more likely than smokers to have visited their GP in the past year $(64.8 \%$ vs $54.9 \%$ ). Observed rates of BI receipt for those who had visited their GP (the sample used in the statistical analysis) suggest a socioeconomic gradient in BI delivery, with a greater proportion of respondents in lower SEP groups reporting that they had received a BI for both smoking and drinking. There appears, however, to be a divergence in the shape of this gradient, with BI receipt for smokers increasing linearly as SEP decreases, while the higher rates of $\mathrm{BI}$ receipt in risky drinkers are concentrated in the most deprived group. These patterns, for social grade, are illustrated in figure 1.

\section{Adjusted models for smoking}

Results for the demographic-adjusted models for receipt of smoking BI (table 3) show that older smokers had significantly greater odds of having received a BI than 18-24years old (eg, OR 2.06; 95\% CI 1.68 to 2.51 for $65+$ years old). Significant effects were also seen for region, with smokers in the South having lower odds of receiving an intervention than those in the North (OR $0.81 ; 95 \%$ CI 0.71 to 0.92 ) and for those with a self-reported disability having greater odds of receiving one than those without (OR $1.37 ; 95 \%$ CI 1.19 to 1.57 ). There was no significant temporal trend in BI delivery.

The addition of behavioural factors to the model (see online supplementary material table S15 for full results) did not change the magnitude or significance of the demographic coefficients, but demonstrated that smokers who were also risky drinkers had lower odds of receiving 

Table 1 Characteristics of survey respondents included in
statistical models (unweighted)

\begin{tabular}{|c|c|c|}
\hline & $\begin{array}{l}\text { Past year smokers } \\
(n=6513), \%\end{array}$ & $\begin{array}{l}\text { Risky drinkers } \\
\text { (n=3975), \%s }\end{array}$ \\
\hline \multicolumn{3}{|l|}{ Age, n (\%) } \\
\hline $18-24$ & $1051(16.1)$ & $877(22.1)$ \\
\hline $25-34$ & $1222(18.8)$ & $539(13.6)$ \\
\hline $35-44$ & 1052 (16.2) & $572(14.4)$ \\
\hline $45-54$ & 1126 (17.3) & $741(18.6)$ \\
\hline $55-64$ & $1046(16.1)$ & $643(16.2)$ \\
\hline $65+$ & $991(15.2)$ & $595(15)$ \\
\hline Missing & $25(0.4)$ & $8(0.2)$ \\
\hline \multicolumn{3}{|l|}{ Sex, n (\%) } \\
\hline Male & 3253 (49.9) & 2600 (65.4) \\
\hline Female & $3260(50.1)$ & 1375 (34.6) \\
\hline Missing & $0(0)$ & $0(0)$ \\
\hline \multicolumn{3}{|l|}{ Region, n (\%) } \\
\hline North & 2540 (39) & $1974(49.7)$ \\
\hline Midlands & 1730 (26.6) & $716(18)$ \\
\hline South & 2234 (34.3) & $1282(32.3)$ \\
\hline Missing & $9(0.1)$ & $3(0.1)$ \\
\hline \multicolumn{3}{|c|}{$\begin{array}{l}\text { Children in the } \\
\text { household, } \mathrm{n}(\%)\end{array}$} \\
\hline Yes & $4308(66.1)$ & 3030 (76.2) \\
\hline No & 2205 (33.9) & $945(23.8)$ \\
\hline Missing & $0(0)$ & $0(0)$ \\
\hline \multicolumn{3}{|c|}{ Disability, n (\%) } \\
\hline Yes & $5121(78.6)$ & $3420(86)$ \\
\hline No & 1275 (19.6) & $494(12.4)$ \\
\hline Missing & $117(1.8)$ & $61(1.5)$ \\
\hline \multicolumn{3}{|c|}{ Ethnicity, n (\%) } \\
\hline White & $5812(89.2)$ & 3813 (95.9) \\
\hline Mixed race & $111(1.7)$ & $59(1.5)$ \\
\hline Asian & $353(5.4)$ & $39(1)$ \\
\hline Black & $147(2.3)$ & $39(1)$ \\
\hline Arab/other & $61(0.9)$ & $10(0.3)$ \\
\hline Missing & $29(0.4)$ & $15(0.4)$ \\
\hline \multicolumn{3}{|c|}{$\begin{array}{l}\text { Motivation to cut down } \\
\text { smoking, } \mathrm{n}(\%)\end{array}$} \\
\hline None & 1649 (25.3) & \\
\hline Moderate & 3415 (52.4) & \\
\hline High & $978(15)$ & \\
\hline Missing & $471(7.2)$ & \\
\hline \multicolumn{3}{|c|}{ Risky drinker, n (\%) } \\
\hline Yes & 5004 (76.8) & \\
\hline No & $1446(22.2)$ & \\
\hline Missing & $63(1)$ & \\
\hline \multicolumn{3}{|c|}{ AUDIT score, n (\%) } \\
\hline $8-15$ & & 3504 (88.2) \\
\hline $16-19$ & & $251(6.3)$ \\
\hline
\end{tabular}

Continued
Table 1 Continued

\begin{tabular}{|c|c|c|}
\hline & $\begin{array}{l}\text { Past year smokers } \\
(n=6513), \%\end{array}$ & $\begin{array}{l}\text { Risky drinkers } \\
\text { ( } n=3975), \% s\end{array}$ \\
\hline $20+$ & & $220(5.5)$ \\
\hline Missing & & $0(0)$ \\
\hline \multicolumn{3}{|c|}{$\begin{array}{l}\text { Motivation to cut down } \\
\text { drinking, } \mathrm{n}(\%)\end{array}$} \\
\hline None & & $2372(59.7)$ \\
\hline Moderate & & $1273(32)$ \\
\hline High & & $296(7.4)$ \\
\hline Missing & & $34(0.9)$ \\
\hline \multicolumn{3}{|c|}{ Past year smoker, n (\%) } \\
\hline Yes & & $2528(63.6)$ \\
\hline No & & 1446 (36.4) \\
\hline Missing & & $1(0)$ \\
\hline
\end{tabular}

AUDIT, Alcohol Use Disorders Identification Test.

a smoking BI (OR 0.84; 95\% CI 0.73 to 0.97 ) and that there was a strong association with both moderate (OR $1.42 ; 95 \%$ CI 1.25 to 1.63 ) and high levels of motivation to cut down or quit smoking (OR 2.14; $95 \%$ CI 1.79 to 2.57) and BI receipt. Finally, the addition of socioeconomic measures to the models showed significantly increased levels of $\mathrm{BI}$ receipt in social grades $\mathrm{D}$ and $\mathrm{E}$ compared with grade $\mathrm{AB}$ (OR 1.26; 95\% CI 1.02 to 1.55 and OR 1.30; $95 \%$ CI 1.05 to 1.61 , respectively). Significant increases in BI receipt were also observed in those with A-levels and no formal qualifications compared with university-level qualifications (OR 1.24; 95\% CI 1.02 to 1.51 and OR $1.24 ; 95 \%$ CI 1.03 to 1.50 , respectively), but no significant association employment status or housing tenure was identified.

\section{Adjusted models for risky drinking}

Results for the demographic-adjusted logistic regression models for alcohol BIs (table 4) showed a similar age gradient to the smoking models, with all risky drinkers aged 35+ having odds at least twice as high of having received a $\mathrm{BI}$ as those under 24 (eg, OR 2.68; 95\% CI 1.53 to 4.71 for $65+$ years old). Unlike for smoking, there was a significant gender effect, with women having lower odds of receiving an intervention (OR 0.68; 95\% CI 0.49 to 0.93$)$. There were no significant effects for region or time, but again, disability was a significant predictor of BI receipt (OR 3.47; 95\% CI 2.54 to 4.74 ).

The addition of behavioural factors to the model (see online supplementary table S16 for full results) substantially increased the slope of the age gradient, with the OR for over 65+ compared with 18-24years old increasing to 5.00 (95\% CI 2.71 to 9.23 ). The effect of disability was reduced, although still significant (OR 2.27; 95\% CI 1.57 to 3.27 ) and we saw an additional significant effect for Arab/other ethnic groups compared with the white group (OR 8.64; 95\% CI 1.81 to 41.21). Of the additional explanatory factors, smoking did not significantly predict 


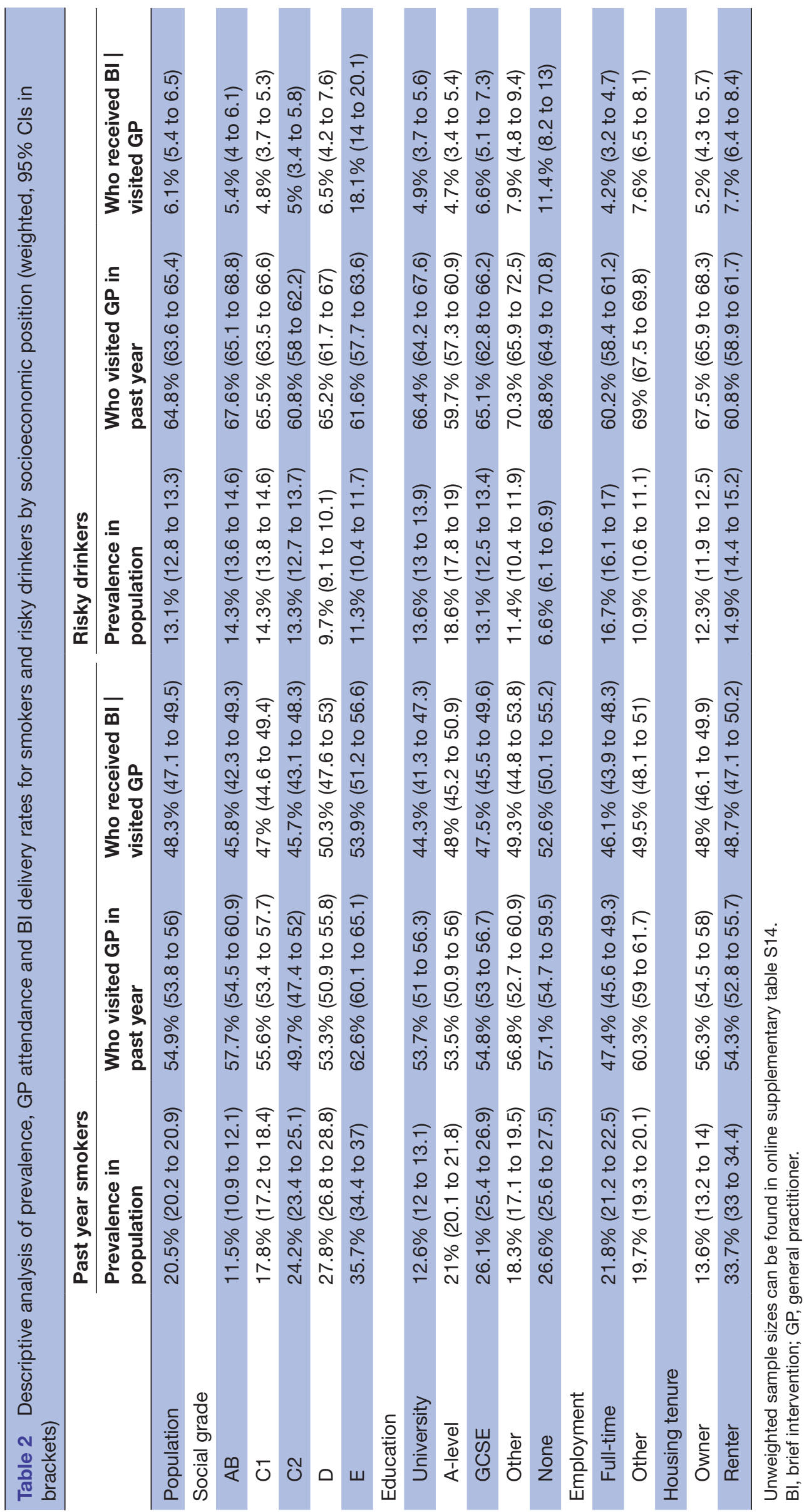


A

Prevalence of risk behaviour

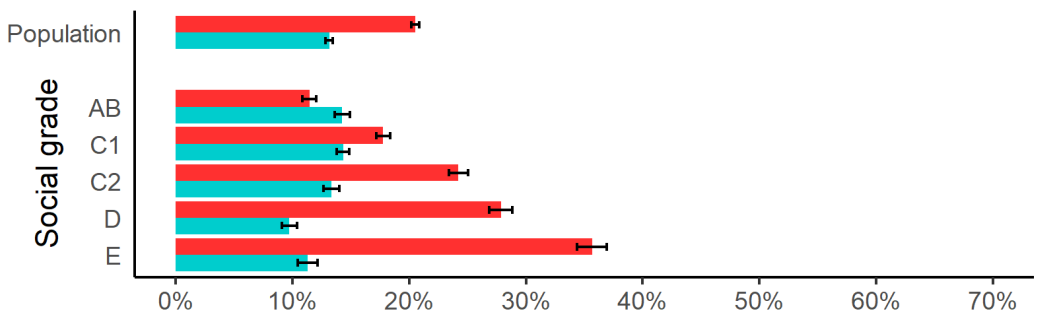

B

Proportion of at-risk population visiting a GP in the past year

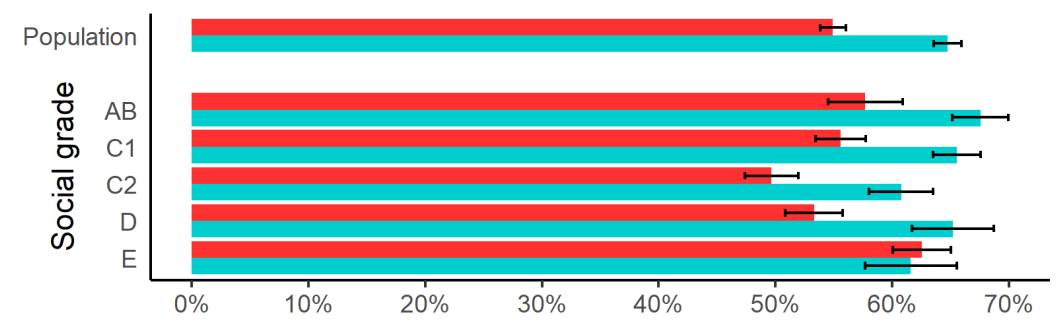

Smoker

Risky drinker

\section{Proportion of at-risk population visiting a GP in the past year who received a $\mathrm{BI}$}

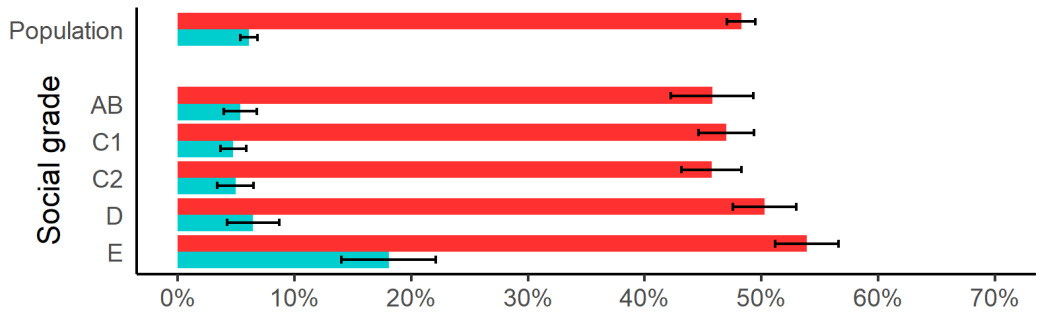

Figure 1 Unadjusted socioeconomic gradients in prevalence, GP attendance and BI receipt for smokers and risky drinkers. BI, brief intervention; GP, general practitioner.

BI receipt for alcohol, but motivation to reduce drinking did, with both moderate (OR 2.85; 95\% CI 2.00 to 4.05 ) and high levels (OR 5.17; 95\% CI 3.29 to 8.14) significantly associated with $\mathrm{BI}$ receipt. Level of alcohol use was also a very strong predictor of BI receipt, with high-risk drinkers having almost three times the odds of having received a BI (OR 2.94; 95\% CI 1.81 to 4.79 ) and potentially dependent drinkers almost 12 times the odds (OR 11.84; $95 \%$ CI 7.77 to 18.04 ).

Adding socioeconomic factors to the model did not further change the magnitude or significance of the other coefficients, but we saw a significant increase in BI receipt for the lowest social grade (E) compared with the highest (OR 2.11; 95\% CI 1.27 to 3.52). There was no significant effect of education, but not being in full-time employment (OR 1.56; 95\% CI 1.08 to 2.25) and not being a homeowner (OR 1.55; 95\% CI 1.09 to 2.20 ) significantly increased the likelihood of receiving a BI. The effects of all four socioeconomic measures on both smoking and alcohol BI receipt are illustrated in figure 2, highlighting the relatively larger scale of the socioeconomic gradients for alcohol compared with smoking.

\section{DISCUSSION}

Our findings show that there is a socioeconomic gradient in BI delivery for both smokers and risky drinkers, with those in the lowest socioeconomic groups more likely to receive an intervention, although there is considerable uncertainty around the exact slope of this gradient. This gradient is not accounted for by differences in demographic characteristics or smoking and drinking behaviour and appears to be stronger for alcohol than for smoking. The analysis also illustrates that, despite clinical guidelines recommending BI for both smokers and risky drinkers, an individual who has attended primary care in the past year is eight times more likely to report receiving an intervention if they are a smoker compared with a risky drinker. For both smoking and drinking, there is a clear age gradient, with greater levels of BI delivery in older age groups, in spite of the fact that the highest rates of prevalence of risky drinking being in the youngest age group. Perhaps surprisingly, smokers who were also risky drinkers were less likely to have received a BI for their smoking than those who were not. The very heaviest drinkers, consuming at potentially dependent levels, are 
ర̄

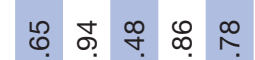

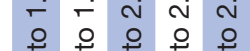

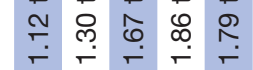

๓ᄄ口

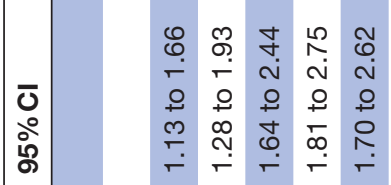

$\frac{9}{2}$
$\frac{.}{0}$
$\frac{c}{0}$
क
to

ธ

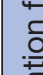

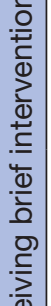

这

눙

믕

产

竞

委

$\frac{0}{0}$

䨌

đั

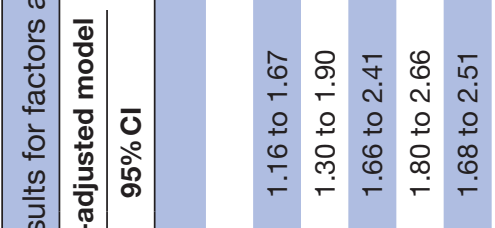

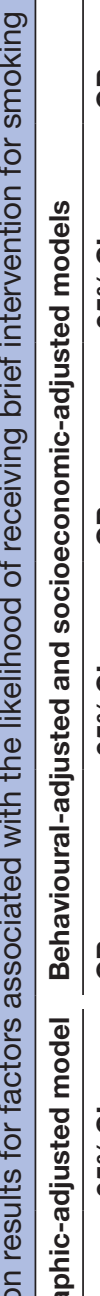

क

产

은

.0.0

m

$\frac{\sqrt{\frac{0}{6}}}{\frac{0}{6}}$

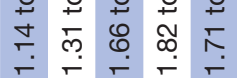

뚱

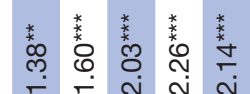

$\infty$ ๑

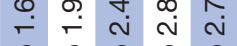

우 우 우 우 우

†.

ब

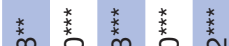

ભ

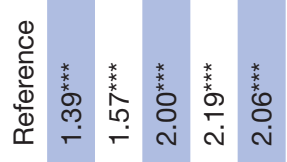

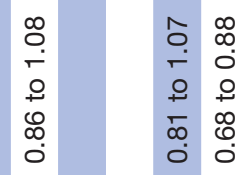

๑ே

$\stackrel{\infty}{\circ}$

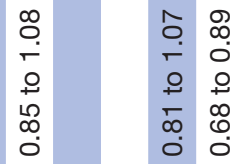

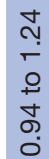

$\stackrel{\infty}{r}$

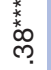

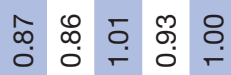

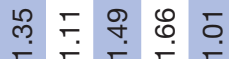

웅ㅇㅇㅇ

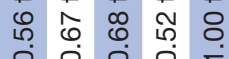

임

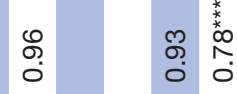

암 둗 웅

인

$\begin{array}{lll}0 & & 0 \\ 0 & 0 & 0 \\ 0 & 0 & 0 \\ 0 & 0 & 0 \\ 0 & 0 & 0\end{array}$

盟 $\quad \begin{aligned} & m \\ & 0\end{aligned}$

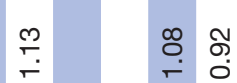

요 운

万.

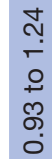

?ำ

웅

ㄱ.

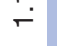

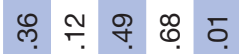

厂

$\begin{array}{lllll}0 & \widehat{0} & 0 & \mathbb{N} & 0 \\ 0 & 0 & 0 \\ 0 & 0 & 0 & 0 \\ 0 & 0 & 0\end{array}$

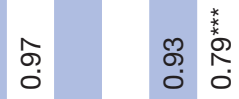

$\stackrel{\infty}{\stackrel{\circ}{\Gamma}}$

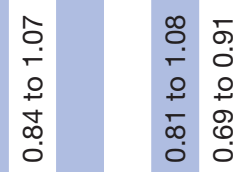

ঙ̣

요

o़

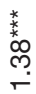

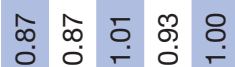

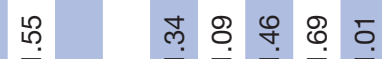

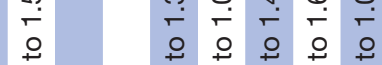

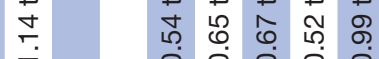

$\stackrel{\circ}{\circ}$

ํㅜ

-

คำ

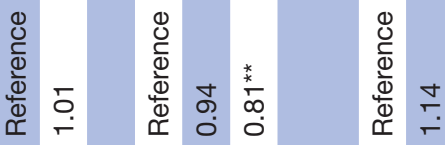

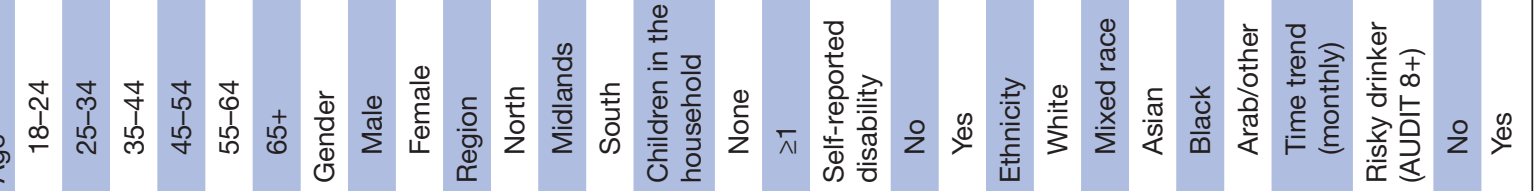

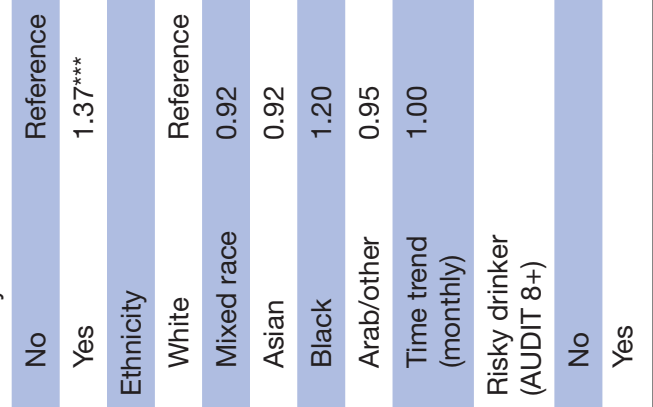




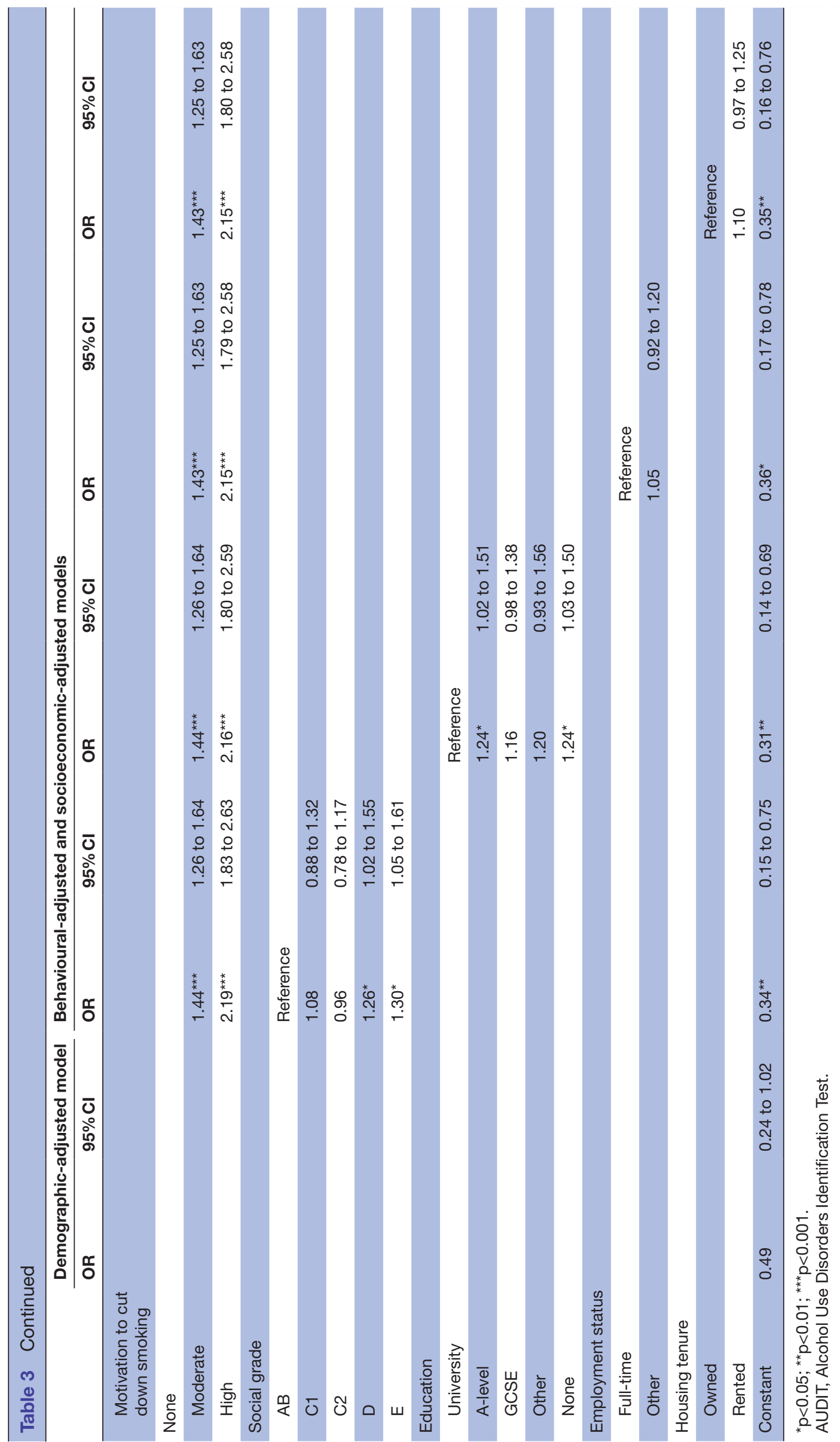

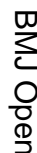

竞

음

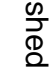

क

$\stackrel{\overrightarrow{0}}{\vec{\Xi}}$



응.

$\stackrel{\oplus}{1}$

กิ

N

$\stackrel{+}{+}$

윽

㐫

옹

○

잉

잉

$\stackrel{2}{\overrightarrow{3}}$

吾

흘

긍.

혹.

옥

옥

을.

N

స్ల

Q

$\stackrel{0}{\overparen{D}}$

$\stackrel{9}{+}$

꿍

ญั

뭉

음 


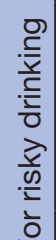

ত

œ

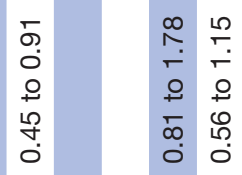

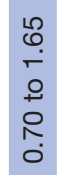

t

둥

일

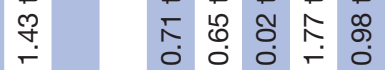

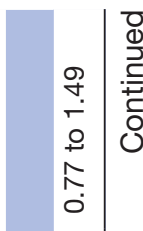

美

움

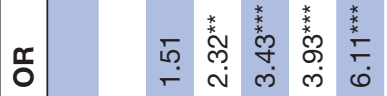

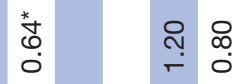

$\stackrel{\infty}{\stackrel{0}{+}}$

त ले

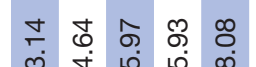

ত̃.

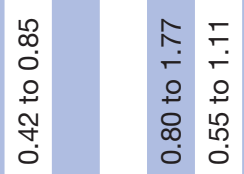

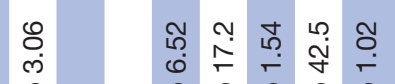

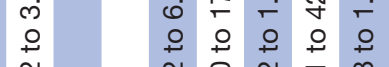

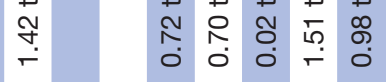

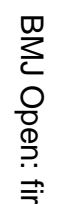

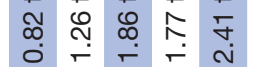

๘़

웅

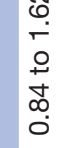

들

뜽

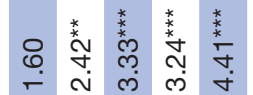

莃

$\stackrel{8}{\stackrel{\circ}{-}}$

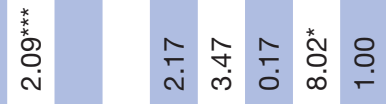

$\stackrel{0}{\check{r}}$

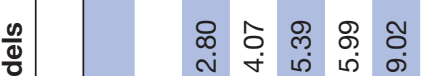

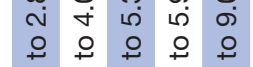

每

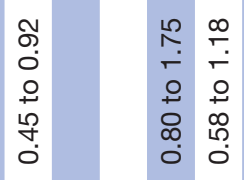

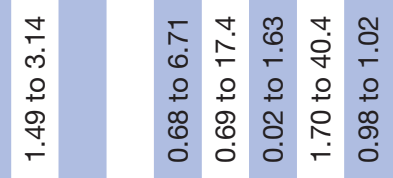

ธิธ

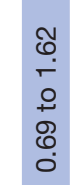

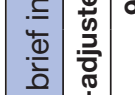

을

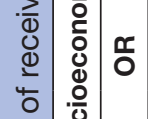

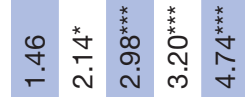

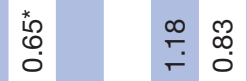

$\stackrel{8}{\circ}$

党

$\stackrel{n}{\check{r}}$

$\stackrel{1}{\infty} \infty$ ก

ง

$\circ$ 우 0 .

ᄉ

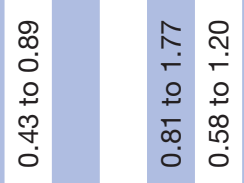

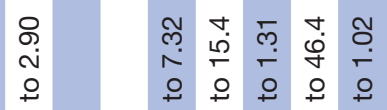

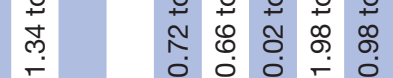

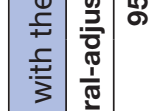

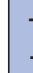

$\frac{\pi}{0}$

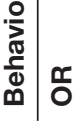

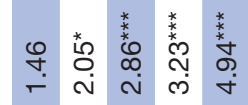

㐘

$\stackrel{8}{\circ}$

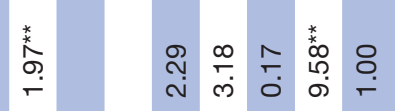

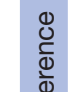

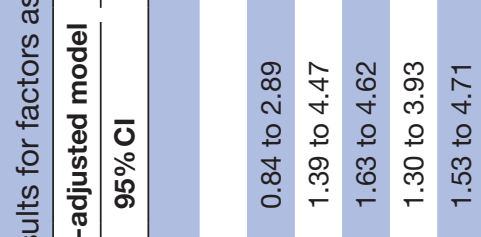

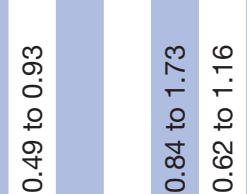

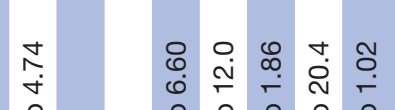

아의

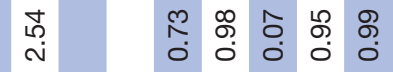

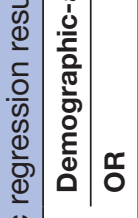

$\stackrel{0}{0}$

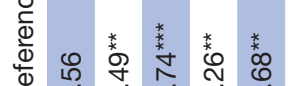

:

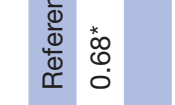

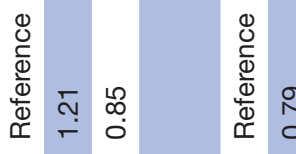

䓪类

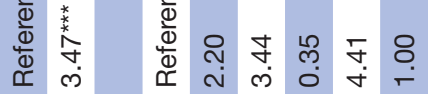

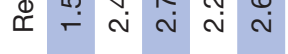

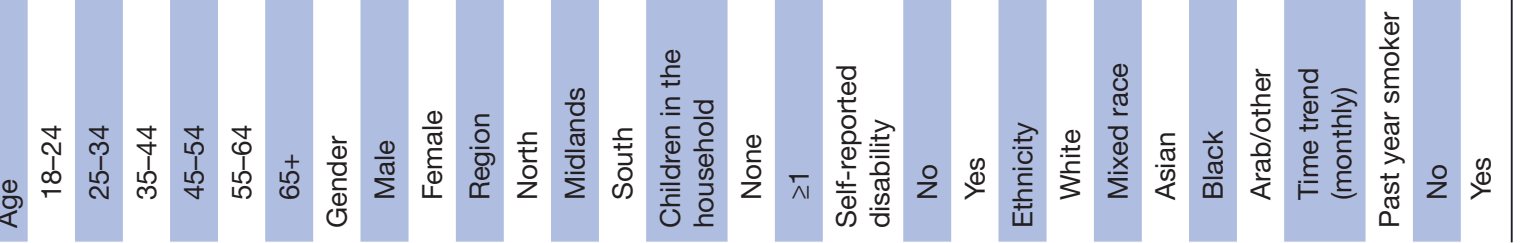




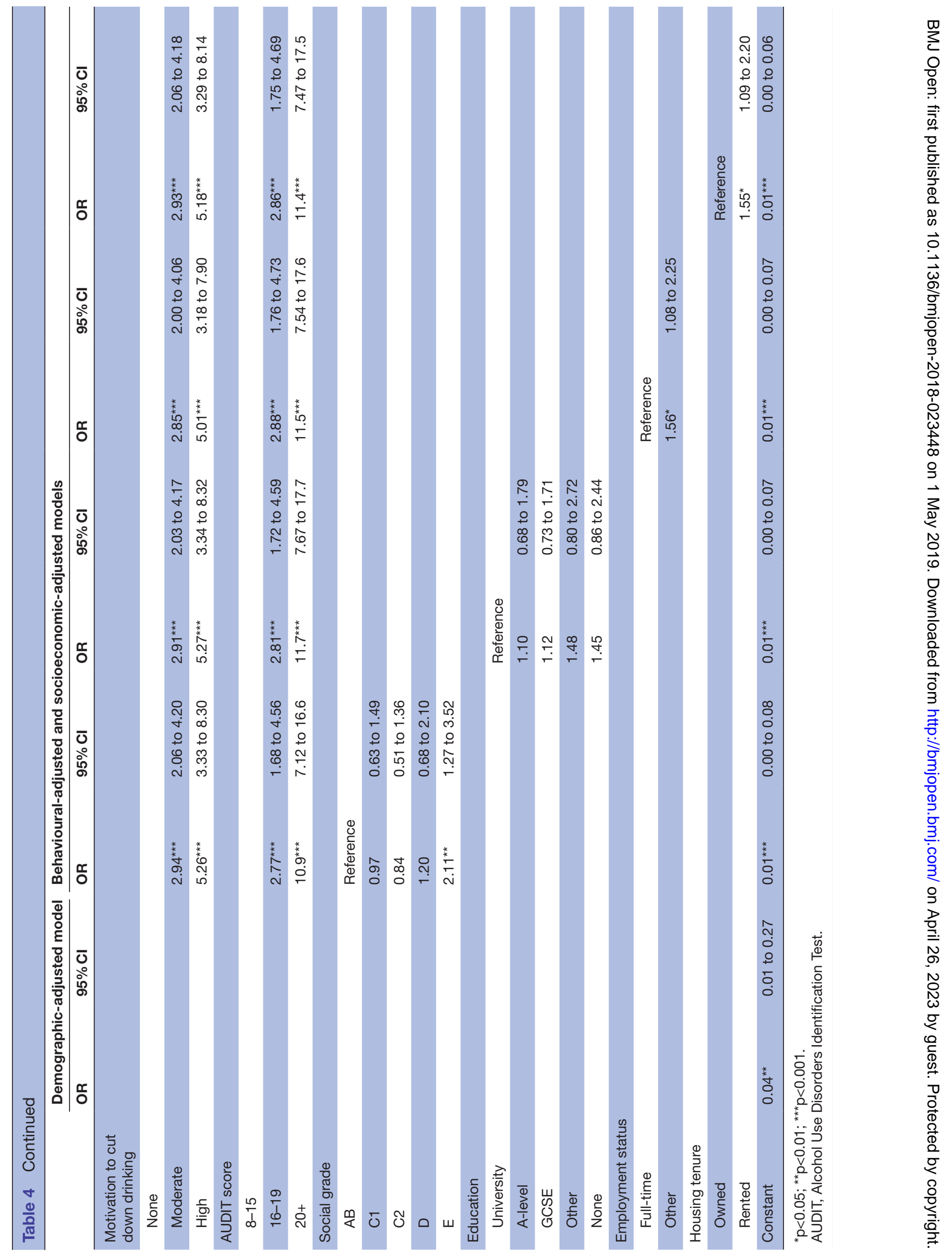




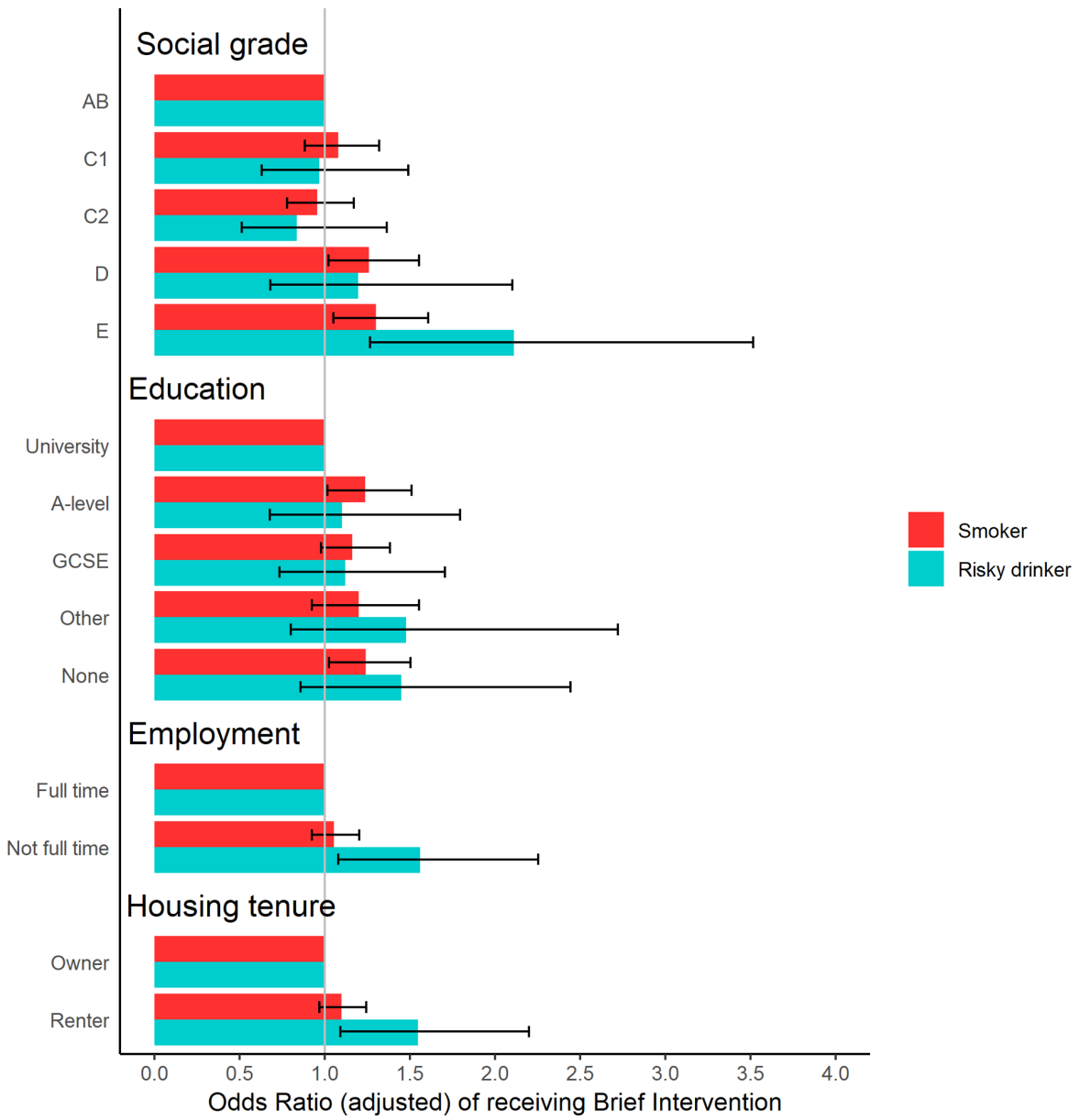

Figure 2 Independent, fully adjusted, association of socioeconomic position with OR of receiving a brief intervention for smoking or risky drinking.

almost 12 times more likely to have received an alcohol intervention than those drinking at lower, but still risky, levels. These findings were robust to alternative data assumptions (see online supplementary material).

Our study represents, to the best of our knowledge, the first detailed exploration of the potential of BIs for both smoking and alcohol to reduce, or increase, inequalities in health. We used data from a large, nationally representative survey and our findings are based on patients' own reporting of having received an intervention. While such a measure may be subject to recall bias, it likely provides a better indicator of patient experience than routine data recorded by practitioners $^{33}$ and is not subject to known biases in practitioner recording. ${ }^{34}$ We explored multiple measures of SEP, finding similar results across all measures, although the effect of increased BI delivery appears more closely associated with low social grade than low levels of education.

There are several important limitations to our study, which should be considered alongside our findings. First, our definition of what constitutes a BI is fairly broad, including anyone who reported receiving advice from a primary care practitioner and that there may be unobserved inequalities in the extent to which different groups receive different intensities of intervention or in the quality of content or delivery of the BI. Second, patient characteristics, including drinking/smoking status and motivation to cut down or quit, are recorded after the BI has taken place. As a result, we cannot establish whether the strong association between motivation and likelihood of $\mathrm{BI}$ receipt is a function of treatment-seeking behaviour in patients who are already motivated to reduce their smoking or drinking, of motivation increasing after receipt of a $\mathrm{BI}$ or of more motivated patients being more likely to recall having received an intervention. Finally, while smoking rates in the Toolkit data are very similar to those reported in other national surveys, ${ }^{35}$ the observed prevalence of risky drinking of $13.1 \%$ is substantially lower than other estimates (eg, 19.7\% in the 2014 Adult Psychiatric Morbidity Survey ${ }^{36}$ ), although it is unclear what effect, if any, this may have on the study results.

Two, much smaller, UK studies conducted in 1996 looked at the relationship between occupation and rates of alcohol BI receipt in risky drinkers, finding no clear socioeconomic gradient. ${ }^{37} 38$ Another, Finnish study also found no significant association, ${ }^{39}$ perhaps suggesting that socioeconomic gradients in BI delivery may not be consistent across different contexts. Previous studies have found similar disparities to those we find between delivery rates of BI for smoking and risky drinking, ${ }^{17}{ }^{40}$ as well as similarly higher levels of BI receipt among primary care patients at older 
ages, ${ }^{41}$ with greater motivation to quit or cut down ${ }^{42}$ and for risky drinkers with higher AUDIT scores. ${ }^{43}$ Numerous explanations for the relatively low rate of BI delivery for risky drinking have been suggested, including a lack of training and resources and the attitudes and beliefs of both practitioners and patients. ${ }^{44-46}$

It is not clear why BI delivery appeared highest in lower socioeconomic groups after adjustment for a range of sociodemographic, drinking and smoking characteristics. Presenting with a chronic disease-likely related to smoking or alcohol-is associated with receipt of BI. ${ }^{17}$ The underlying reason for the GP visit was not recorded in the current study but it is possible that smoking-related or alcohol-related illness is more likely to present in low compared with high SEP smokers or risky drinkers, respectively. ${ }^{47}$

Our analysis focuses on the receipt of BIs for patients who reported attending primary care in the past year. There are likely to be additional socioeconomic gradients in terms of access to, use of and quality of primary care services, which will moderate any overall impact of BIs on health inequalities. ${ }^{48-51}$ We should also consider the potential for differential effectiveness of the intervention across socioeconomic groups. If BIs are more effective at changing the behaviour of those in higher SEP groups then this may mitigate any potential inequality-reducing effects. There is little evidence to support the existence of such a gradient in effectiveness for alcohol, ${ }^{52}$ although there is some suggestion that this may be in part because lower SEP groups are more likely to drop out of BI trials. ${ }^{53}$ For smoking, a recent study does suggest that there may be some degree of inequality in long-term outcomes for smoking cessation interventions. ${ }^{54} \mathrm{~A}$ holistic view of the full impact of screening and BI programmes should consider the impact of these potential SEP gradients, which may attenuate the positive gradients identified in the present study, alongside existing negative gradients in alcohol-related and tobacco-related harm. Such is the severity of these gradients in harm, with those in the lowest SEP groups experiencing rates of harm several times greater than those in the highest groups even after adjusting for drinking and smoking behaviour, ${ }^{48}$ that an intervention could have a negative SEP gradient in terms of its effects on alcohol consumption and/or smoking, while still reducing overall inequalities. Further research in this area is urgently needed to understand the full impact that BI programmes may be having on socioeconomic inequalities. This need is particularly acute given National Health Service England's recent decision to incentivise secondary care providers to deliver large-scale BI programmes for both smoking and risky drinking under the latest Commissioning for Quality and Innovation scheme. Although similar gradients in the prevalence of both smoking and risky drinking, as well as associated harm, have been observed in many countries, ${ }^{55} 56$ primary care systems can vary widely and it is, therefore, unclear how generalisable our findings are beyond England. Future research into this area, particularly in low-income and middle-income countries, could help design screening and $\mathrm{BI}$ programmes to maximise their potential to reduce inequalities in health.
These findings provide the first evidence that BI programmes may help to reduce inequalities in smoking-related and alcohol-related health, although better evidence is needed on the extent to which conflicting socioeconomic gradients in delivery and, potentially, intervention effectiveness interact with existing gradients in health. There is considerable scope for the potential effect on inequalities to be increased if intervention rates can be raised, particularly for drinking.

\section{Author affiliations}

${ }^{1}$ School of Health and Related Research, University of Sheffield, Sheffield, UK ${ }^{2}$ Department of Psychology and Language Sciences, University College London, London, UK

${ }^{3}$ Department of Clinical, Educational and Health Psychology, UCL, London, UK ${ }^{4}$ Institute of Health and Society, Newcastle University, Newcastle upon Tyne, UK ${ }^{5}$ Centre for Outcomes Research and Effectiveness, University College London, London, UK

Contributors CA conceived of and designed the study with input from JB, EB, $D G, P B, E F S K, S M$ and PM. CA performed the analysis and wrote the first draft of the paper. All authors commented on this and subsequent versions and read and approved the final manuscript.

Funding This work was supported by a research innovation grant from Alcohol Change UK (R2016/01). The ATS is funded by the National Institute for Health Research (NIHR)'s School for Public Health Research (SPHR). SPHR is a partnership between the Universities of Sheffield; Bristol; Cambridge; Exeter; UCL; The London School for Hygiene and Tropical Medicine; the LiLaC; a collaboration between the Universities of Liverpool, and Lancaster and Fuse; The Centre for Translational Research in Public Health, a collaboration between Newcastle, Durham, Northumbria, Sunderland and Teesside Universities. The Smoking Toolkit Study is currently primarily funded by Cancer Research UK (C1417/A14135, C36048/ A11654 and C44576/A19501) and has previously also been funded by Pfizer, GlaxoSmithKline and the Department of Health. JB's post is funded by a fellowship from the Society for the Study of Addiction, and Cancer Research UK also provide support (C1417/A14135).

Disclaimer The views are those of the author(s) and not necessarily those of the NHS, the NIHR or the Department of Health.

Competing interests CA, EB and PB's salaries are funded or part-funded by the National Institute for Health Research (NIHR)'s School for Public Health Research (SPHR) and all have received funding from Cancer Research UK (CRUK); EFSK is a senior investigator in SPHR. JB is funded by CRUK and the Society for the Study of Addiction; SM is funded by CRUK. CA has received funding related to commissioned research from Systembolaget, the Swedish government-owned alcohol retail monopoly. CA and PM have received funding related to commissioned research from Alko, the Finnish government-owned alcohol retail monopoly. JB and EB have both received unrestricted research funding from Pfizer relating to smoking cessation studies.

Patient consent for publication Not required.

Ethics approval Ethical approval for the Smoking Toolkit Study (STS) was originally granted by the UCL Ethics Committee (ID 0498/001). Approval for the ATS was granted by the same committee as an extension of the STS. The data were collected by Ipsos Mori and anonymised when received by study authors. Explicit verbal agreement and willingness to answer questions voluntarily were recorded electronically by Ipsos Mori. Participants were also given a printed information sheet. This standard was agreed by the UCL Ethics Committee.

Provenance and peer review Not commissioned; externally peer reviewed.

Data sharing statement The data set analysed during the current study is available from the corresponding author on reasonable request.

Open access This is an open access article distributed in accordance with the Creative Commons Attribution Non Commercial (CC BY-NC 4.0) license, which permits others to distribute, remix, adapt, build upon this work non-commercially, and license their derivative works on different terms, provided the original work is properly cited, appropriate credit is given, any changes made indicated, and the use is non-commercial. See: http:// creativecommons.org/licenses/by-nc/4.0/. 


\section{REFERENCES}

1. Forouzanfar MH, Afshin A, Alexander LT, et al. Global, regional, and national comparative risk assessment of 79 behavioural, environmental and occupational, and metabolic risks or clusters of risks, 1990-2015: a systematic analysis for the Global Burden of Disease Study 2015. Lancet 2016;388:1659-724.

2. Siegler V, Al-Hamad A, Johnson B, et al. Social inequalities in alcohol-related adult mortality by National Statistics Socioeconomic Classification, England and Wales, 2001-03. Health Stat Q 2011;50:4-39.

3. Marmot M. Fair society, healthy lives, the Marmot review. 2010 http:// www.instituteofhealthequity.org/projects/fair-society-healthy-livesthe-marmot-review

4. Hiscock R, Bauld L, Amos A, et al. Socioeconomic status and smoking: a review. Ann N Y Acad Sci 2012;1248:107-23.

5. Holmes J, Meng Y, Meier PS, et al. Effects of minimum unit pricing for alcohol on different income and socioeconomic groups: a modelling study. Lancet 2014;383:1655-64.

6. Lewer D, Meier P, Beard E, et al. Unravelling the alcohol harm paradox: a population-based study of social gradients across very heavy drinking thresholds. BMC Public Health 2016;16:599.

7. Bellis MA, Hughes $\mathrm{K}$, Nicholls J, et al. The alcohol harm paradox: using a national survey to explore how alcohol may disproportionately impact health in deprived individuals. BMC Public Health 2016;16:111.

8. Katikireddi SV, Whitley E, Lewsey J, et al. Socioeconomic status as an effect modifier of alcohol consumption and harm: analysis of linked cohort data. Lancet Public Health 2017;2:e267-e276.

9. Beard E, Brown J, West R, et al. Deconstructing the alcohol harm paradox: a population based survey of adults in England. PLoS One 2016;11:e0160666.

10. Stead L, Bergson G, Lancaster T. Physician advice for smoking cessation. Cochrane Libr 2008 http://onlinelibrary.wiley.com/doi/

11. Aveyard P, Begh R, Parsons A, et al. Brief opportunistic smoking cessation interventions: a systematic review and meta-analysis to compare advice to quit and offer of assistance. Addiction 2012;107:1066-73.

12. Kaner EF, Beyer FR, Muirhead C, et al. Effectiveness of brief alcohol interventions in primary care populations. Cochrane Database Syst Rev 2018;2:CD004148.

13. Angus $C$, Latimer N, Preston L, et al. What are the implications for policy makers? A systematic review of the cost-effectiveness of screening and brief interventions for alcohol misuse in primary care. Front Psychiatry 2014;5.

14. National Institute of Health and Clinical Excellence (NICE). Stop smoking interventions and services: NICE guideline [NG92]. 2018 https://www.nice.org.uk/guidance/ng92

15. National Institute of Health and Clinical Excellence (NICE). PH24 Alcohol-use disorders: preventing harmful drinking. 2010 www.nice. org.uk/guidance/ph24

16. England PH; Department of Health,. NHS health check programme: best practice guidance. London 2013 http://www.healthcheck.nhs. uk/document.php?o=456

17. Taggar JS, Coleman T, Lewis S, et al. The impact of the Quality and Outcomes Framework (QOF) on the recording of smoking targets in primary care medical records: cross-sectional analyses from The Health Improvement Network (THIN) database. BMC Public Health 2012;12:329.

18. Brown J, West R, Angus $\mathrm{C}$, et al. Comparison of brief interventions in primary care on smoking and excessive alcohol consumption: a population survey in England. Br J Gen Pract 2016;66:e1-9.

19. Anderson $P$, Bendtsen $P$, Spak $F$, et al. Improving the delivery of brief interventions for heavy drinking in primary health care: outcome results of the Optimizing Delivery of Health Care Intervention (ODHIN) five-country cluster randomized factorial trial. Addiction 2016;111:1935-45.

20. Denny $\mathrm{CH}$, Hungerford DW, McKnight-Eily LR, et al. Self-reported prevalence of alcohol screening among U.S. adults. Am J Prev Med 2016;50:380-3.

21. Rehm J, Allamani A, Della Vedova R, et al. General practitioners recognizing alcohol dependence: a large cross-sectional study in 6 European countries. Ann Fam Med 2015;13:28-32.

22. Lorenc T, Petticrew M, Welch V, et al. What types of interventions generate inequalities? Evidence from systematic reviews. $J$ Epidemiol Community Health 2013;67:190-3.

23. White M, Heywood P. How and why do interventions that increase health overall widen inequalities within populations? Babones S, ed. Health, Inequality and society. Bristol: Policy Press, 2009.

24. Beard E, Brown J, West R, et al. Protocol for a national monthly survey of alcohol use in England with 6-month follow-up: 'the Alcohol Toolkit Study'. BMC Public Health 2015;15:230.
25. Fidler JA, Shahab L, West O, et al. 'The smoking toolkit study': a national study of smoking and smoking cessation in England. BMC Public Health 2011;11:479.

26. Babor TF, Higgins-Biddle JC, Saunders JB, et al. The alcohol use disorders identification test guidelines for use in primary care: World Health Organization, 2001.

27. Collis D. Social grade: A classification tool - Bite sized thought piece. 2009 https://www.ipsos-mori.com/DownloadPublication/1285_ MediaCT thoughtpiece Social Grade July09 V3 WEB.pdf.

28. Graham JW, Olchowski AE, Gilreath TD. How many imputations are really needed? Some practical clarifications of multiple imputation theory. Prev Sci 2007;8:206-13.

29. Rubin DB. Multiple Imputation after 18+ Years. J Am Stat Assoc 1996;91:473-89.

30. StataCorp. Stata statistical software: release 12. 2011

31. Gep B, Tidwell PW. Transformation of the independent variables. Technometrics 1962;4:531.

32. Vandenbroucke JP, et al. Strengthening the Reporting of Observational Studies in Epidemiology (STROBE): explanation and Elaboration. Ann Intern Med 2007;147:W-8.

33. Wilson A, McDonald P. Comparison of patient questionnaire, medica record, and audio tape in assessment of health promotion in general practice consultations. BMJ 1994;309:1483-5.

34. Szatkowski L, McNeill A, Lewis S, et al. A comparison of patient recall of smoking cessation advice with advice recorded in electronic medical records. BMC Public Health 2011;11.

35. Health and Social Care Information Centre. Health survey for England 2014. England: Health and Social Care Information Centre, 2015.

36. Office for National Statistics. Adult psychiatric morbidity survey 2014 Office for National Statistics, 2016.

37. Kaner EF, Heather N, Brodie J, et al. Patient and practitioner characteristics predict brief alcohol intervention in primary care. $\mathrm{Br} \mathrm{J}$ Gen Pract 2001;51:822-7.

38. Lock CA, Kaner EF. Implementation of brief alcohol interventions by nurses in primary care: do non-clinical factors influence practice? Fam Pract 2004;21:270-5.

39. Mäkelä P, Havio M, Seppä K. Alcohol-related discussions in health care-a population view. Addiction 2011;106:1239-48.

40. Khadjesari Z, Marston L, Petersen I, et al. Alcohol consumption screening of newly-registered patients in primary care: a crosssectional analysis. Br J Gen Pract 2013;63:e706-12.

41. Denny $\mathrm{CH}$, Serdula MK, Holtzman D, et al. Physician advice about smoking and drinking: are U.S. adults being informed? Am J Prev Med 2003;24:71-4.

42. Kotz D, Fidler J, West R. Factors associated with the use of aids to cessation in English smokers. Addiction 2009;104:1403-10.

43. Cheeta S, Drummond C, Oyefeso A, et al. Low identification of alcohol use disorders in general practice in England. Addiction 2008;103:766-73.

44. O'Donnell A, Kaner E. Are Brief Alcohol Interventions Adequately Embedded in UK Primary Care? A qualitative study utilising normalisation process theory. Int $J$ Environ Res Public Health 2017;14:350.

45. O'Donnell A, Abidi L, Brown J, et al. Beliefs and attitudes about addressing alcohol consumption in health care: a population survey in England. BMC Public Health 2018;18:391.

46. Kaner E, Rapley T, May C. Seeing through the glass darkly? A qualitative exploration of GPs' drinking and their alcohol intervention practices. Fam Pract 2006;23:481-7.

47. Sadler S, Angus C, Gavens L, et al. Understanding the alcohol harm paradox: an analysis of sex- and condition-specific hospital admissions by socio-economic group for alcohol-associated conditions in England. Addiction 2017;112:808-17.

48. McLean G, Sutton M, Guthrie B. Deprivation and quality of primary care services: evidence for persistence of the inverse care law from the UK Quality and Outcomes Framework. J Epidemiol Community Health 2006;60:917-22.

49. Ellis DA, McQueenie R, McConnachie A, et al. Demographic and practice factors predicting repeated non-attendance in primary care: a national retrospective cohort analysis. Lancet Public Health 2017;2:e551-9.

50. Gulliford MC. Availability of primary care doctors and population health in England: is there an association? J Public Health Med 2002;24:252-4.

51. Watt G. The inverse care law today. Lancet 2002;360:252-4.

52. Littlejohn C. Does socio-economic status influence the acceptability of, attendance for, and outcome of, screening and brief interventions for alcohol misuse: a review. Alcohol Alcohol 2006;41:540-5. 
53. Edwards AG, Rollnick S. Outcome studies of brief alcohol intervention in general practice: the problem of lost subjects. Addiction 1997;92:1699-704.

54. Bauld L, Hiscock R, Dobbie F, et al. English stop-smoking services: one-year outcomes. Int J Environ Res Public Health 2016;13:1175.
55. Sassi F, Belloni A, Mirelman AJ, et al. Equity impacts of price policies to promote healthy behaviours. Lancet 2018;391:2059-70.

56. Mackenbach JP, Stirbu I, Roskam AJ, et al. Socioeconomic inequalities in health in 22 European countries. N Engl $\mathrm{J} \mathrm{Med}$ 2008;358:2468-81. 